\title{
Understanding of Weil's disease among canoeists
}

\author{
Robin Philipp FFOM, FFPHM, Chrissy King RGN, OHNC and \\ Anthony Hughes MPhil, MFPHM \\ Department of Epidemiology and Public Health Medicine, University of Bristol, Bristol, UK
}

\begin{abstract}
Although the risks of contracting Weil's disease in the UK are small, it can be a serious illness. Recently the disease has attracted public interest. This interest has prompted confusion and anxiety among recreational water user groups such as canoeists who had not previously seen themselves as being particularly at risk. In this paper, the experience of symptoms associated with Weil's disease among canoeists, their understanding and perceptions of the disease, and their compliance with preventive advice on the British Canoe Union (BCU) warning card, have been studied. Gaps in understanding and of adherence to preventive advice were identified. Accordingly, it was concluded that health education for canoeists could be improved. Consideration is being given by the BCU to the value of preparing a canoeist instructors' training pack.
\end{abstract}

Keywords: Weil's disease, canoeists, health, understanding, education

In 1991 it was reported that 'Leptospirosis has recently been the subject of increased media attention, prompting confusion and anxiety amongst several groups who have not previously seen themselves as being at risk - such as canoeists and other recreational water users' ${ }^{1}$. Reasons for this interest and the public health response have been reviewed, and it was determined that on average each year in the UK and among 5 million total recreational water users, there are only 2.5 cases of Weil's disease, and one death in every 4 years ${ }^{2}$. These levels of risk are low and less than among the total UK population ${ }^{2}$. Public concern has also prompted the Medical Advisory Panel of the British Canoe Union (BCU), the national governing body of canoeists, to determine risks for their members. In 1990, they calculated that with current estimates of about 1 million persons annually participating in canoeing, the overall risk of a canoeist contracting the illness is about 1:200000. They noted that a canoeist who heeds the preventive advice given is therefore

Address for correspondence: Dr R. Philipp, Department of Epidemiology and Public Health Medicine, University of Bristol, Canynge Hall, Whiteladies Road, Bristol BS8 2PR, UK

(C) 1992 Butterworth-Heinemann Ltd 0306-3674/92/040223-05 several times less likely to contract the illness than he or she is to die in a road traffic accident in any one year (1:9600), and that the chance of death for a canoeist is currently about $1: 333000^{2}$. These levels of risk should be compared with the seven deaths on average each year from diving accidents ${ }^{3}$, some 66 other deaths, including drownings, during water sports activities ${ }^{4}$, and the three or four drowning deaths each year among canoeists ${ }^{2}$. The Public Health Laboratory Service (PHLS) Leptospira Reference Laboratory has noted that for Weil's disease, 'simple precautions may reduce even further the small risk ${ }^{\mathbf{1}}$, and that there is a need to inform people in a balanced and non-alarmist way of the outside chance of contracting the disease and the precautions which could be taken' ${ }^{5}$. Public and professional education with the issue of 'warning cards' to those at risk are, therefore, now widely recommended ${ }^{1,6-9}$.

Extensive education of canoeists is provided to help prevent Weil's disease and because of the risk of contact with contaminated waters when performing eskimo rolls and capsize drill ${ }^{10}$. Since 1983, and on the advice of its Medical Advisory Panel, the BCU issues all its members with a warning card outlining the causes of Weil's disease, how to recognize the symptoms, and giving advice about how to avoid the disease. To help ensure early diagnosis if they develop an influenza-like illness after recent immersion in water, canoeists have been told to show the warning card to their general practitioner ${ }^{11}$. The information given on the warning card is shown in Appendix 1. It advises canoeists to avoid capsize drill on stagnant or slow-moving water (as L. icterohaemorrhagiae are more prevalent there), to wash or shower following canoeing, and to use footwear to avoid cutting their feet. These cards can only be effective if canoeists read and follow the advice given on them.

This study was undertaken among canoeists to examine their experience of symptoms associated with Weil's disease, their understanding and perceptions of the disease, and their compliance with preventive advice on the BCU warning card. It was prepared in support of a World Health Organization (WHO) viewpoint that public perception information is an essential component of any health and safety programme for recreational water exposure ${ }^{12}$. 


\section{Method}

A questionnaire was prepared and three nurses were trained in the aims and method of the study, interviewing techniques, and how to administer the questionnaire. Participants were invited to answer 30 questions about Weil's disease and their compliance with advice on the BCU warning card, and for details of their age, sex and occupation.

In March 1991, the questionnaire was pretested by the three interviewers with six members of Pembroke County Canoeists. These canoeists had all previously attended a lecture on Weil's disease and its prevention given by their Occupational Health Adviser. They had a good understanding of the information on the BCU warning card. There were no differences between the interviewers or canoeists in the way the questionnaires were completed.

The main study population was selected from canoeists attending the Dee Tour event at Llangollen, North Wales, on 9-10 November 1991. This is a weekend when a 12-mile stretch of the River Dee between Cynwyd and Llangollen is open to canoeists for 2 days. The event attracts large numbers of entrants from all areas of the UK. It therefore provided an opportunity to interview a large number of experienced canoeists. Permission to approach the canoeists as they left the water was obtained from the Welsh Canoe Association (WCA) who organized the event. The BCU recognizes the WCA as the governing body for canoeists in Wales, and with full reciprocal rights.

At the event, canoeists from different parts of the UK were identified by direct questioning. As members of any one club could be more likely to have shared their views on Weil's disease or to have shared experiences, participants for the study were deliberately sought from a wide range of clubs. Registration details and the numbers attending could not be obtained before the event. Canoeists also entered and left the river throughout the 12-mile section where the event was held and at different times during the weekend. Therefore it was not possible to interview a truly random sample stratified for different geographical areas of residence. Participants were asked to remain anonymous. Their confidentiality was assured.

Data were entered on a PC file database and analysed with the SPSS/PC ${ }^{13}$ statistical package.

\section{Results}

Of the 1100 canoeists who registered for the event, 212 were invited to take part in the study and all agreed to be interviewed. Time constraints prevented more canoeists being recruited.

All the participants were members of the BCU and had received a copy of the $B C U$ warning card. Of the 212 completed questionnaires, seven were excluded as they had been completed by persons with occupational exposures to untreated water and in work where they are likely to have been given additional preventive advice to that routinely provided by the BCU. These exclusions comprised four environmental health officers, two water company employees, and one farmer. Therefore 205 questionnaires remained for analysis.

Among the 205 participants, there were 169 males and 36 females. Their mean age was 28 years (range 12-72 years). They were grouped into three standards of canoeing proficiency:

Low:

(novice, one star, two star or three star) $=88$ participants;

Intermediate: (inland proficiency, sea proficiency, and four star or above) $=59$ participants;

High: (senior instructor and coach) $=58$ participants.

In the answers to each question, there were, however, no statistically significant differences between these groups ( $\chi^{2}$ test; $P>0.05$ ). Accordingly, data in the tables have been presented together for all respondents.

Knowledge of Weil's disease among the 205 respondents is shown in Table 1.

Among the 194 respondents who had heard of Weil's disease, $48 \%$ had heard through the BCU Handbook, 16\% from canoeing magazines, 9\% from canoeing leaflets, and $27 \%$ from 'other' sources such as word-of-mouth and the news media. In all, 52 respondents $(25 \%)$, knew someone who had experienced the disease. Of these, 11 reportedly knew someone who 'had not made a full recovery'.

The experience of relevant environmental factors and of health problems associated with Weil's disease among respondents are shown in Table 2.

The behaviour of respondents when compared with advice given on the BCU warning card is shown in Table 3.

Table 1. Knowledge of Weil's disease among 205 canoeists

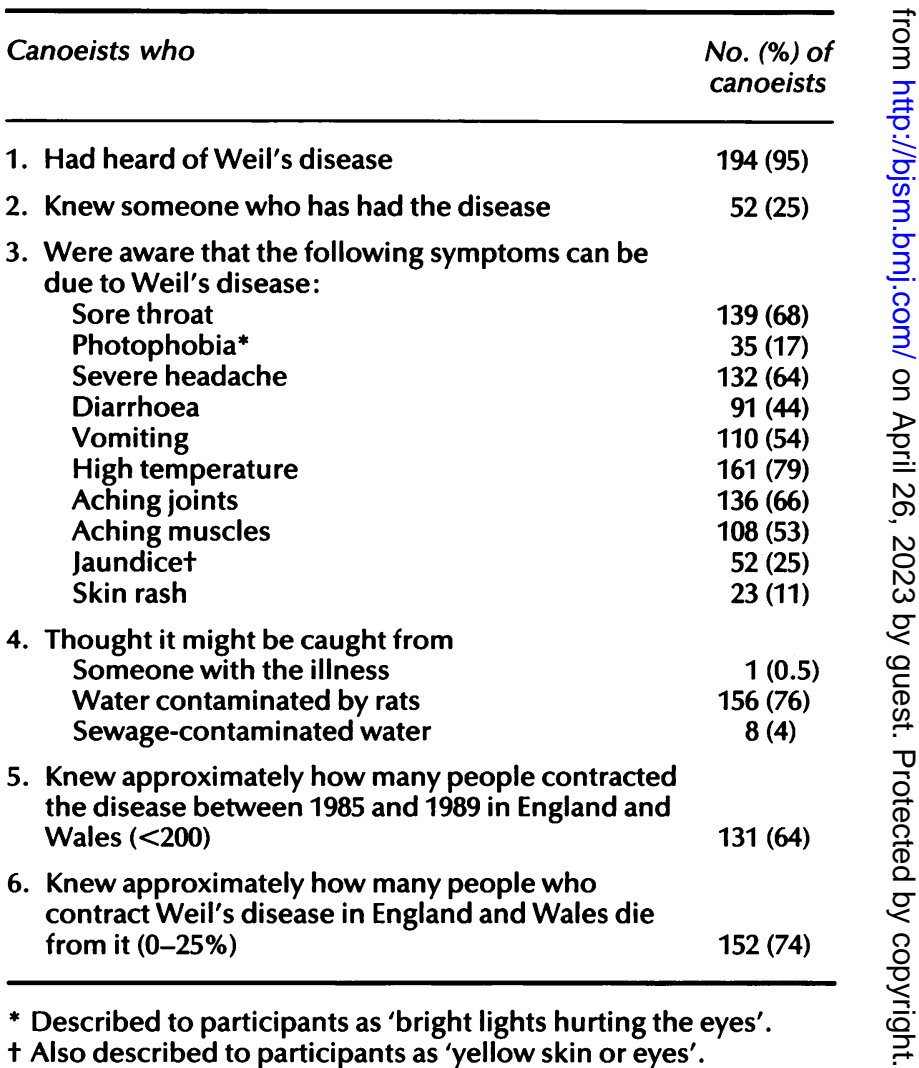

* Described to participants as 'bright lights hurting the eyes'.
+ Also described to participants as 'yellow skin or eyes'. 
Table 2. Environmental exposures and morbidity experience among 205 canoeists

\begin{tabular}{lr}
\hline Canoeists who & $\begin{array}{r}\text { No. (\%) of } \\
\text { canoeists }\end{array}$ \\
\hline $\begin{array}{l}\text { 1. In the past year had seen on the river bank near } \\
\text { to where they canoe } \\
\quad \text { Rats }\end{array}$ & $79(39)$ \\
$\quad \begin{array}{l}\text { Sewage outlets } \\
\text { Rubbish/litter }\end{array}$ & $163(80)$ \\
$\begin{array}{l}\text { 2. Had ever experienced a 'flu-like' illness after } \\
\text { canoeing }\end{array}$ & $108(53)$ \\
$\begin{array}{l}\text { 3. Had ever been to a doctor with 'flu' after canoeing } \\
\text { 4. Had ever told their doctor they were a canoeist }\end{array}$ & $48(23)$ \\
$\begin{array}{l}\text { 5. The possibility of Weil's disease had ever been } \\
\text { suggested by their doctor }\end{array}$ & $13(6)$ \\
$\begin{array}{l}\text { 6. Ever suggested to their doctor the possibility of } \\
\text { Weil's disease }\end{array}$ & $36(18)$ \\
$\begin{array}{l}\text { 7. Had ever been given a blood test for Weil's } \\
\text { disease by their doctor }\end{array}$ & $22(11)$
\end{tabular}

Table 3. Behaviour of 205 canoeists when compared with advice given on the British Canoe Union warning card

\begin{tabular}{lc}
\hline Canoeists who & $\begin{array}{c}\text { No. (\%) of } \\
\text { canoeists }\end{array}$ \\
\hline 1. Usually canoe on placid water & $81(40)$ \\
2. Take part in capsize drill on placid water & $129(63)$ \\
3. Ever canoe on moving water & $204(100)$ \\
4. Take part in capsize drill on moving water & $166(81)$ \\
5. Take part in capsize drill on both moving and & \\
still water & $110(54)$ \\
6. Use footwear when canoeing and if so, if it is & $200(98)$ \\
$\quad$ Open sandals & $5(2)$ \\
Wetsuit boots & $164(80)$ \\
Trainers & $28(14)$ \\
Other & $8(4)$ \\
7. After canoeing & \\
Always shower & $112(55)$ \\
Sometimes shower & $18(9)$ \\
Never shower & $75(37)$ \\
\hline
\end{tabular}

\section{Discussion}

The findings of this study support discrepancies in risk perception between 'experts' and 'the public', and the need for better public education; that have been identified by the British Medical Association and the Royal Society ${ }^{14,15}$. For example, in Table 1, although $95 \%$ of respondents had heard of Weil's disease and $25 \%$ reported that they knew someone who had experienced the disease, $36 \%$ thought Weil's disease was contracted by more than 40 persons each year, and despite contrary information on the BCU warning card, $26 \%$ thought that it had a case fatality rate of greater than $25 \%$.

As the BCU warning card had been issued to all respondents, their awareness of symptoms associated with Weil's disease is deficient. For example, in Table 1 only $17 \%$ associated photophobia with Weil's disease, despite having the symptom explained to them as 'bright lights hurting the eyes', and only $25 \%$ associated jaundice with the disease, despite it also being described to them as 'yellow skin or eyes'. However, as also shown in Table 1, their understanding of the patterns of disease transmission was much better in that $76 \%$ knew Weil's disease could be contracted from water contaminated by rats. Correctly, few respondents thought it was acquired by contact with someone with the illness or from sewage-contaminated water.

In Britain, attention has been drawn to the problem of uncollected refuse and discarded litter ${ }^{16}$ and the need for improved disposal facilities in areas where the water is used for recreation ${ }^{17}$. It has also been reported that only $46 \%$ of adults believe preventing litter is a personal responsibility and that in the under 25 age range, only $23 \%$ believe it to be a personal matter ${ }^{18}$. The finding in Table 2 that $90 \%$ of respondents had in the past year seen rubbish or litter on the river bank near to where they canoe, is therefore not unexpected. Furthermore, rats are often found in sewers and on river banks. For example, in 1990 it was estimated that $70 \%$ of London's sewers were infested with rats $^{19}$, and it was recently reported that in 1991, on a typical autumn evening at Holme Pierrepoint, a white-water canoe slalom course in Nottinghamshire, 'it would have been possible to see 100 rats on the bank of the Trent ${ }^{20}$. Accordingly, and as $80 \%$ of respondents had noticed sewer outlets near to where they canoe and all of them took part in river canoeing, it is not surprising that $39 \%$ of respondents had seen rats in the past year near to where they canoe. Of those who had seen sewer outlets, $40 \%(65 / 163)$ had also seen rats near to where they canoe, and of those who saw rats, $82 \%(65 / 79)$ had also noticed sewer outlets near to where they canoe.

It is interesting that $53 \%$ of respondents had experienced a 'flu-like' illness after canoeing. This finding contrasts with at least one study of 74 dinghy sailors in which $14 \%(10 / 74)$ reported that they had experienced upper respiratory symptoms after participating in their sport ${ }^{21}$. Unlike these dinghy sailors, of whom only two attended their doctor, $23 \%$ of canoeists had gone to their doctor with 'flu' symptoms. Despite advice on the BCU warning card, three canoeists who visited their doctor with 'flu' symptoms did not tell the doctor that they were canoeists. It is important to do so as appropriate clinical management depends on medical awareness of any relevant exposures ${ }^{22,23}$. It may explain why the possibility of Weil's disease was only suggested by the doctor for $26 \%(6 / 23)$ of these canoeists who went to their doctor with 'flu' symptoms. Of the respondents, $78 \%(18 / 23)$ did suggest the possibility of Weil's disease to their doctor, a finding that probably explains why, despite the disease being so uncommon, $48 \%(11 / 23)$ of respondents who attended their doctor were apparently tested for leptospiral antibodies.

In Table 3 it is shown that despite advice on the BCU warning card to 'avoid capsize drill on stagnant or slow-moving water', $63 \%$ of respondents undertook this drill. Although there were no statistically significant differences between groups of respon- 
dents with different levels of canoeing proficiency $\left(\chi^{2}\right.$ test; $P>0.05)$, it seems reasonable to expect that less experienced canoeists are more likely to practice their capsize drill on stagnant or slow-moving water. Nevertheless, despite the BCU advice, $54 \%$ of respondents still choose to take part in capsize drill on placid water as well as on moving water. Also shown in Table 3, is that adherence to the BCU advice about footwear is much more common and that although showers may not be readily available, $55 \%$ of respondents reported they always shower after canoeing.

Despite the deficiencies of understanding and adherence to preventive advice identified in this study, the health risks associated with recreational water exposure to $L$. icterohaemorrhagiae and other microbial hazards are limited ${ }^{24}$. Furthermore, the risks associated with recreational water exposure can never be reduced to zero ${ }^{3}$. The BMA has noted that: 'what safe means, to most people, is that for a given activity the associated risks have been reduced to 'negligible' levels, and to make something safe enough is to reduce the risk to the level of 'acceptability'3. For Weil's disease, the hazards are being managed by PHLS surveillance for the size of the problem, widespread professional and public education programmes, and prompt clinical management of suspected cases ${ }^{2}$. Nevertheless, the findings of this study suggest that health education for canoeists could be improved. For example, first aid is taught on courses for canoeing instructors and canoe lifeguards. The training could, perhaps, be extended to reinforce advice stated on the BCU warning card, the importance of protective clothing and the need for safe hygienic practices. Given the widespread public interest in Weil's disease ${ }^{2}$, a canoeist instructors' training pack could also be prepared to help them impart appropriate preventive advice for Weil's disease on their courses. One practical format is as a series of problem-management questionnaires (PMQs) in which participants are encouraged to identify their own learning needs. The preparation and use of such PMQs in environmental medicine have been described ${ }^{25}$.

\section{Acknowledgements}

We are grateful to Helen Pike and Stuart Roy, medical students, University of Bristol, for their help in designing the questionnaire, to Mrs Kathie McGhie and Mrs Teresa Mitchell for their assistance with the interviewing, and to members of the Welsh Canoe Association and the British Canoe Union who participated in the study.

\section{References}

1 Ferguson IR. Leptospirosis update. Br Med J 1991; 302: 128-9.

2 Philipp R. The public health response to increasing awareness about Weil's disease associated with recreational water exposure. Environ Health 1992; 100: 292-7.

3 British Medical Association. Living with Risk. Penguin Books, 1990: 284.

4 Office of Population Censuses and Surveys (OPCS) Monitor, DH4 88/6, 13 December 1988.

5 Waitkins S. Leptospirosis - a water related health hazard. In: Polluted Water and Recreation. Report of a National Seminar, The Central Council of Physical Recreation, 1990: 44.

6 Consumers' Association. Weil's disease Leptospirosis. Which Way to Health. London: The Consumers' Association, 1991; August: 122-3 (Editorial).

7 Philipp R. Health and safety aspects of recreational water exposure. Communicable Disease Report 1989, 11 August, CDR 89/32, 3-4.

8 Ferguson IR. Leptospirosis update: 1985-89. Communicable Disease Report 1990, 27 April, CDR 90/17, 3-4.

9 Gompertz D. Leptospirosis update. Br Med J 1991; 302: 471.

10 Anonymous. Communicable disease report: Leptospirosis. Editorial. I Public Health Med 1991: 13(1): 52

11 Whitehead JRE. Some medical problems associated with water sports. The Royal College of General Practitioners, Members Reference Book. London: RCGP. 1989: 257-60.

12 WHO. Final Report of the Working Group on Health Impact of Human Exposure to Recreational Fresh and Marine Waters, Rimini, Italy, 27 February-2 March 1990. WHO Regional Office for Europe ICP/RUD 153, May 1990, 3033r, 1-74.

13 Statistical package for the social sciences. SPSS/PC + V4.O Base Package, MJ Norusis, SPSS, Chicago, Illinois, USA.

14 British Medical Association. Hazardous Waste and Human Health. A Report from the BMA Professional and Scientific Division. Oxford: Oxford University Press 1991: 1-242.

15 The Royal Society. Risk Assessment: Report of a Royal Society Study Group. London: The Royal Society 1983: 198.

16 Semple AB. Our dirty towns. Br Med J 1989; 299: 634-5.

17 South Western Regional Health Authority. Health hazards associated with the recreational use of water. A report. South Western Regional Health Authority, 1991; December: 1-57.

18 Ashworth G. Changing public attitudes to litter. Environmental Health, London 1990; 98: 239-42.

19 Rendle S. Rats: are they a water industry problem? Water Bulletin 1990; No. 392: 3-4.

20 Anonymous. Trent Weil's disease. Editorial. Canoeist 1992; July: 8.

21 Philipp R. Health risks associated with exposure to cyanobacteria (blue-green algae) when dinghy sailing. Health Hygiene 1992; 13: 110-14.

22 Philipp R, Shaw C, Donald F, Bird A. What do you work with? Br Med J 1985: 291: 412.

23 Philipp R, Hughes AO. Hospital admissions and occupational histories. Lancet 1983; 1: 129-30.

24 Philipp R. Risk assessment and microbiological hazards associated with recreational water sports. Rev Med Microbiol 1991; 2: 208-14.

25 Philipp R. Problem-management questionnaires as a student learning tool in environmental medicine. Public Health 1992; 106: 289-99. 


\section{WEIL'S DISEASE}

RIVERS, PONDS AND CANALS ARE USUALLY INFECTED WITH A BACTERIUM WHICH CAN CAUSE WEIL'S DISEASE. MOST OF THE TIME WEIL'S DISEASE MAY TAKE THE FORM OF A CHILL, POSSIBLY RESEMBLE AN ATTACK OF FLU.

\section{WEIL'S DISEASE CAN CAUSE SERIOUS ILLNESS OR DEATH}

\section{FOR IDENTIFICATION OF THE BACTERIUM WITHIN 24 HOURS YOUR DOCTOR IS REMINDED OF THE EXISTENCE OF:}

The Leptospirosis Reference Unit Public Health Laboratory County Hospital HEREFORD, HR1 2ER 0432274696

Results of blood tests have been known to take two weeks or longer through the normal laboratory system. Deaths and serious illnesses have occurred because of slow identification. The local public health laboratory should be equipped to undertake an ELISA test, from which a result can be obtained within $3 \mathrm{hrs}$ of commencement. Otherwise the sample should be sent direct to the Leptospirosis Reference Unit.

\section{KEEP THIS SAFELY WITH YOUR MEMBERSHIP CARD}

\section{WEIL'S DISEASE}

\section{Dr. John Whitehead, BCU Medical Advisory Panel}

\section{What is it?}

Weil's disease is a bacterial infection carried in rats' urine which contaminates water and wet river banks. The bacteria does not survive for long in dry conditions. It can occur in any water, including swift streams and rivers. The likelihood of becoming infected is greater from stagnant or slow moving waterways.

\section{How serious is it?}

It can be a serious illness requiring hospital treatment and can lead to kidney or liver failure. One patient in 19 dies with it. Weil's Disease is a notifiable illness.
How do I catch it?

The bacteria are absorbed through the skin and mucous membranes of the mouth and eyes. It gets into the blood stream more easily if you have a minor cut on your feet or if you do capsize drill or rolling.

\section{What should I do about it?}

If you fall ill with the symptoms, after canoeing, particularly from 3-19 days following, and have any of the features in the case history CALL YOUR DOCTOR EARLY. The most common symptoms are: temperature, an influenza-like illness, and joint and muscle pains (pains in the calf muscles are often particularly noticeable). Jaundice and/or conjunctivitis may be present, or develop, although the absence of any of these symptoms does not mean that the illness is not Weil's Disease - nor does a symptom in isolation necessarily indicate that Weil's Disease is present. TELL YOUR DOCTOR YOU HAVE BEEN CANOEING AND WHERE. IF WEIL'S DISEASE IS SUSPECTED ANTIBIOTICS MUST BE ADMINISTERED IMMEDIATELY - WITHIN 24-48 HOURS OF ONSET. A BLOOD TEST SHOULD BE UNDERTAKEN TO CONFIRM THIS NOTIFIABLE ILLNESS. IF THE LOCAL PUBLIC HEALTH LABORATORY IS NOT EQUIPPED TO UNDERTAKE AN ELISA TEST, THE SAMPLE SHOULD BE SENT DIRECT TO THE LEPTOSPIROSIS REFERENCE UNIT AT HEREFORD. TELL THE WCA WHO WILL LET THEIR MEDICAL PANEL KNOW ABOUT IT.

\section{In Summary}

- Avoid capsize drill or rolling in stagnant or slow moving water.

- Wash or shower after canoeing.

- Cover minor scratches on exposed parts of the body with water-proof plaster.

- Use foot-wear to avoid cutting feet.

- If you have a flu-like illness after canoeing go to your GP early - tell him/her you are a canoeist and show this card.

- Let the WCA know if you contract the disease or if there is the likelihood of any local ban on canoeing because of the disease. 